\title{
KESIAPAN GURU SEKOLAH DASAR DALAM PELAKSANAAN PEMBELAJARAN MATEMATIKA YANG BERBASIS PENDIDIKAN BERKARAKTER DI KOTA KARAWANG JAWA BARAT
}

\author{
Ramlan$^{1}$, Vevi Hermawan ${ }^{2}$ \\ Dosen Pendidikan Matematika FKIP UNPAS \\ 1ramlanmsn@unpas.ac.id, ${ }^{2}$ vevi_pmat@unpas.ac.id
}

\begin{abstract}
Abstrak
Proses pembelajaran matematika yang melibatkan pengetahuan moral, perasaan moral dan tindakan moral, akan melahirkan bangsa yang cerdas dan berkarakter. Hal ini sangat tergantung pada guru, sebab implementasi pendidikan karakter dimulai dari kelas. Penelitian ini bertujuan untuk mengetahui kesiapan guru sekolah dasar dalam mengimplementasikan pembelajaran matematika yang berbasis pendidikan karakter. Penelitian ini menggunakan metode deskriptif analisis kualitatif, sedangkan teknik pengumpulan data menggunakan Focus Group Discussion (FGD). Dilihat dari aspek pengetahuan dan kesiapan, dapat disimpulkan bahwa guru-guru sekolah dasar belum siap untuk melaksanakan pembelajaran matematika yang berbasis pendidikan karakter. Kepada guru-guru sekolah dasar disarankan untuk meningkatkan kompetensinya, dengan melakukan studi terhadap konsep dan kebijakan tentang pendidikan karakter bangsa. Konsep dan kebijakan yang dimaksud adalah : Kebijakan Nasional Pembangunan Karakter Bangsa Tahun 2010-2025; Desain Induk Pendidkan Karakter Tahun 2010; dan Pengembangan Pendidikan Budaya dan Karakter Bangsa Tahun 2010.
\end{abstract}

Kata kunci : Pembelajaran Matematika, Pendidikan Karakter

\begin{abstract}
Mathematics learning process which involves moral knowing, moral feeling, and moral action will produce intelligent and character of a nation. This really depends on the teacher, because the character education implementation should start from the class. This research aims to find of the elementary school's teachers readiness, on mathematics learning implementation which based on character education. The research method in this research used descriptive analysis qualitative, with focus group discussion as the data collection technique. Viewed from the knowledge aspect and the readiness of the teacher on teaching mathematics, it can be concluded that the elementary school teacher are not ready to implement the mathematics learning process which based on character education. The elementary school teachers are recommended to improve their competences by doing some study of the concepts and policies which is related to the character education development. The concept and the policies are: Kebijakan Nasional Pembangunan Karakter Bangsa Tahun 2010-2025; Desain Induk Pendidkan Karakter Tahun 2010; and Pengembangan Pendidikan Budaya dan Karakter Bangsa Tahun 2010.
\end{abstract}

Keyword : Mathemathics learning, Character education 


\section{A. PENDahuluan}

Fenomena bangsa Indonesia yang tengah mengalami 'krisis moral' saat ini bukanlah berita yang baru muncul kepermukaan (public), tapi sesungguhnya sudah berlangsung cukup lama.Sejak bangsa Indonesia memproklamirkan menjadi bangsa yang demokratis melalui gerakan reformasi pada tahun 1999, malahan menjadi bangsa yang terbiasa bersikap dan bertindak anarkis, intoleran, korupsi, saling fitnah, bahkan peristiwa pembunuhan terjadi di hampir di seluruh wilayah Negara Kesatuan Republik Indonesia.

Sikap dan tindakan pelajar dan mahasiswa yang masih terjadi pada saat sekarang : (1) kebiasaan "mencontek" pada saat ulangan atau ujian masih dilakukan; (2) keinginan lulus dengan cara mudah dan tanpa kerja keras pada saat ujian nasional, menyebabkan mereka berusaha mencari jawaban dengan cara tidak ber-etika; (3) plagiarism atau penjiplakan karya ilmiah di kalangan mahasiswa juga bersifat masif; (4) tawuran antar pelajar dan antar mahasiswa; (5) meminum minuman keras, pergaulan bebas, dan penyalahgunaan narkoba; dan (6) "geng pelajar" dan "geng motor" yang seringkali menjurus pada tindakan kriminal seperti penganiayaan, bahkan pembunuhan. (Nuh, 2010).

Para pengamat dari berbagai bidang disiplin ilmu, berpandangan bahwa fenomena bangsa kita yang seperti di atas terkait dengan karakter manusia. Manusia sejak lahir memiliki karakter yang terbentuk melalui faktor keturunan. Potensi yang merupakan bawaan sejak lahir ini tidak mungkin akan berkembang menjadi karakter yang bermanfaat bagi kehidupan jika tidak ada proses pengembangan melalui pendidikan.

Pada buku berjudul "Desain Induk Pendidikan Karakter" (Nuh, 2010), menjelaskan bahwa konsep strategi pendidikan karakter pada konteks mikro sesungguhnya harus diintegrasikan dalam setiap proses pembelajaran yang dipimpin langsung oleh guru pada setiap mata pelajaran di kelas. Sehingga guru-lah yang memiliki peranan penting dan bertanggungjawab utama dalam membentuk karakter peserta didik. 


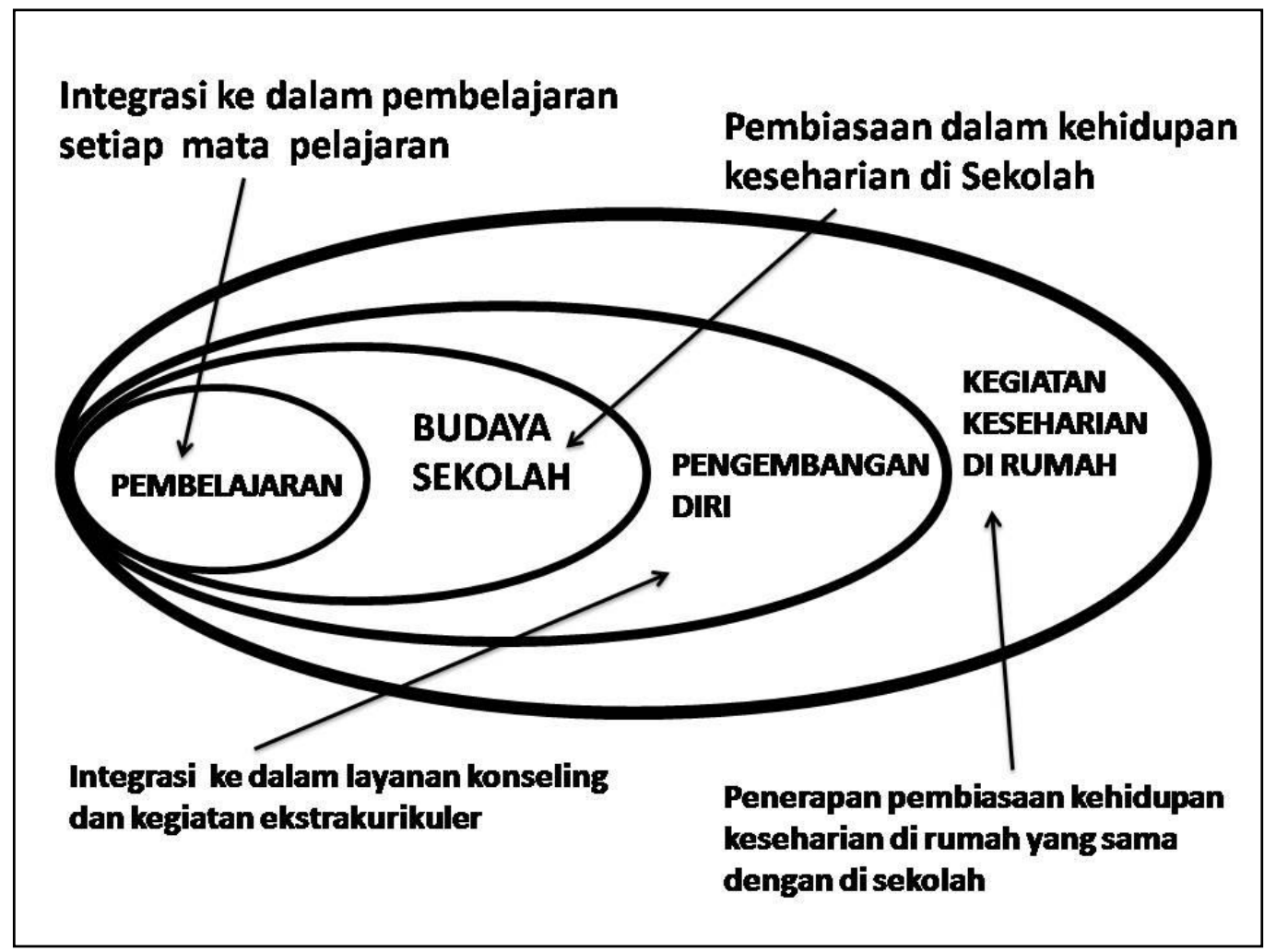

Gambar 1 .

Konsep Strategi Pendidikan Karakter konteks mikro pada Desain Induk Pendidikan Karakter

Melihat konsep pendidikan karakter pada konteks mikro sebagaimana dijelaskan pada gambar diatas, menegaskan bahwa guru memiliki tugas yang pertama dan utama untuk mengembangkan dan membentuk karakter peserta didik, sebab harus dimulai dari kelas. Pada kurikulum nasional ( kurikulum 2013 ), setiap guru di sekolah dasar diharuskan bisa mengajarkan seluruh mata pelajaran atau dengan istilah lain harus menjadi "guru kelas". Tidak hanya itu, setiap guru harus bisa mengajar mata pelajaran yang bermuatan pendidikan berkarakter.

Salah satu mata pelajaran yang wajib diajarkan mulai anak masuk sekolah dasar sampai dengan sekolah menengah atas adalah matematika. Pada hakikatnya matematika merupakan hasil pemikiran manusia yang berhubungan dengan penalaran. Dengan bernalar semestinya anak harus bisa membedakan yang baik dan yang tidak baik, yang bermanfaat atau tidak bermanfaat. Jadi dengan belajar matematika, ada proses pengembangan diri anak menuju pembentukan pribadi yang lebih baik. 
Pada buku "Pengembangan Pendidikan Budaya dan Karakter Bangsa" (KEMENDIKNAS, 2010), menegaskan bahwa nilai-nilai yang harus dikembangkan dalam pendidikan karakter bangsa diidentifikasi dari sumber-sumber Agama, Pancasila, Budaya, dan Tujuan Pendidikan Nasional. Pada buku tersebut menegaskan pula bahwa tujuan pendidikan nasional memuat berbagai nilai kemanusiaan yang harus dimiliki warga negara Indonesia. Oleh karena itu, tujuan pendidikan nasional adalah sumber yang paling operasional dalam pengembangan budaya dan karakter bangsa.

Berdasarkan keempat sumber nilai itu, teridentifikasi sejumlah nilai-nilai untuk dikembangkan dalam pendidikan budaya dan karakter bangsa, yaitu : (1) Religius; (2) Jujur; (3) Toleransi; (4) Disiplin; (5) Kerja keras; (6) Kreatif; (7) Mandiri; (8) Demokratis; (9) Rasa ingin tahu; (10) Semangat kebangsaan; (11) Cinta Tanah Air; (12) Menghargai Prestasi;(13) Bersahabat/Komunikatif; (14) Cinta damai; (15) Gemar membaca; (16) Peduli lingkungan; (17) Peduli sosial; dan (18) Tanggung-jawab. Khusus untuk mata pelajaran matematika di sekolah dasar kelas 1 sampai dengan kelas 3, nilai karakter yang diutamakan adalah : (1) Teliti; (2) Tekun; (3) Kerja keras; (4) Rasa ingin tahu; dan (5) Pantang menyerah.

Dengan demikian guru dalam mengajar matematika misalnya tidak sekadar mengajarkan bagaimana agar peserta didik mengetahui bahwa $2 \times 5=10$, tapi melalui proses pembelajaran operasi perkalian, bagaimana karakter siswa akan berkembang atau terbentuk, sehingga memiliki nilai-nilai teliti, tekun, kerja keras, rasa ingin tahu atau pantang menyerah. Hal ini sangat terkait dengan bagaimana guru melaksanakan proses pembelajarannya yang berbasis pendidikan karakter.

Nilai dalam pendidikan matematika menurut Nik (2009) dapat diklasifikasikan dalam tiga kategori yang saling terkait, yaitu nilai pendidikan umum, nilai pendidikan matematika, dan nilai matematika. Nilai pendidikan umum merujuk pada nilai moral, etika, atau akhlak yang dikembangkan melalui pendidikan matematika, tetapi nilai tersebut tidak berkaitan secara langsung dengan pengetahuan matematika. Misalnya berbicara tentang timbangan sebagai alat ukur (konsep kesamaan dan ketidaksamaan dalam matematika), guru perlu mengungkapkan tentang kebenaran, keadilan dan kejujuran. Nilai pendidikan matematika merujuk nilai yang berkaitan dengan kebiasaan dan norma atau aturan dalam pembelajaran matematika. Nilai pendidkan matematika misalnya ketepatan, kejelasan, 
konsisten, tekun, kreatif, sistematis, berpikir fleksibel, mengikuti prosedur, mematuhi algoritma. Sedangkan nilai matematika merujuk nilai tentang ciri dan sumber pengetahuan matematika yang dikembangkan dalam pendidikan matematika.

Soedjadi (2000) menegaskan bahwa pembelajaran matematika tidak hanya mengandung nilai edukasi yang bersifat mencerdaskan siswa tetapi juga nilai edukasi yang membantu membentuk pribadi siswa. Memang untuk dapat mengetahui apakah nilai edukasi pembentukan pribadi siswa telah tercapai tidaklah mudah, lebih-lebih dalam waktu yang singkat. Untuk itu diperlukan upaya terencana, kontinu dan pengamatan yang cukup lama. Selama ini nilai-nilai yang terkandung dalam pembelajaran matematika diharapkan akan tercapai dengan sendirinya. Melalui pembelajaran matematika diharapkan dengan sendirinya pada siswa akan cermat dalam melakukan pekerjaan, akan kritis dan konsisten dalam bersikap, akan jujur dan lain sebagainya yang disebut by-change. Akan tetapi sekarang kita lebih memerlukan perencanaan pembelajaran matematika yang secara sengaja memasukan pembelajaran nilai-nilai tersebut yang disebut pembelajaran bydesign. Dalam pembelajaran ini perlu dilengkapi dengan tujuan domain afektif maupun psikomotor yang memerlukan instrumen pengukuran.

Jadi sesungguhnya dalam pembelajaran untuk membentuk karakter, sangat mengutamakan proses. Guru matematika agar tidak merasa sudah mencapai tujuan pembelajaran apabila peserta didik telah hapal rumus segitiga yaitu $12 / 2$ Alas X Tinggi, tapi bagaimana proses menuju hafalnya rumus tersebut berdampak pada terbentuknya karakter, misalnya karakter teliti, tekun atau rasa ingin tahu.

Proses pembelajaran untuk membentuk karakter peserta didik, menurut Lickona (1992) memerlukan keterpaduan ketiga komponen, yaitu: (1) Pengetahuan Moral (Moral Knowing), meliputi: Kesadaran moral, Pengetahuan nilai moral, Pengetahuan perspektif, Pemikiran moral, Pengambilan keputuasan, dan Pengetahuan pribadi (Moral awareness, Knowing moral values, Perspective-Talking, Moral reasoning, Decision making and Selfknowledge); (2) Perasaan Moral (Moral Feeling),meliputi: Hati Nurani, Harga Diri, Empati, Mencintai Hal Yang baik, Kendali diri, dan Kerendahan hati(conscience,self esteem, empathy, loving the good, self-control, humility), dan (3) Tindakan Moral (moral action), meliputi : Kompetensi, Keinginan dan Kebiasaan (competence, will, and habit). 
Persoalannya adalah bagaimana kesiapan guru di sekolah dasar, dalam mengajar matematika agar peserta didik tidak sekadar mendapatkan pengetahuan matematika, tapi bisa berdampak pada terbentuknya karakter peserta didik. Merujuk pada gagasan Lickona (1992), guru harus berkompeten untuk mengimplementasikan proses pembelajaran dengan melibatkan ketiga komponen, yaitu pengetahuan moral, perasaan moral, dan tindakan moral.

Penelitian ini bermaksud untuk mengetahui kesiapan guru sekolah dasar dalam mengimplementasikan proses pembelajaran matematika yang dapat membentuk karakter peserta didik. Hasil penelitian ini diharapkan mendapat temuan yang dapat berkontribusi pada penguatan pembinaan pendidikan karakter yang sedang menjadi perhatian pemerintah.

\section{B. METODE PENELITIAN}

Penelitian ini menggunakan metode deskriptif analitis kualitatif, adapun teknik pengumpulan data menggunakan Focus Group Discussion (FGD). Responden dikumpulkan di sebuah ruangan untuk menerima pertanyaan-pertanyaan peneliti, mereka diberikan kebebasan untuk menyampaikan jawaban dan mengeluarkan pendapat dari pertanyaan-pertanyaan yang telah disiapkan oleh peneliti.

Responden pada penelitian ini adalah guru-guru sekolah dasar (kelas 1, kelas 2, dan kelas 3) di wilayah kota Karawang Jawa Barat, yang diundang secara khusus oleh peneliti melalui kerjasama dengan Kepala Dinas Pendidikan kota Karawang. Jumlah guru sekolah dasar yang hadir adalah sebanyak 48 orang dari 21 sekolah.

Merujuk dari Krueger (1988), bahwa FGD bertujuan untuk mengumpulkan data mengenai persepsi dan pandangan responden terhadap sesuatu, tidak berusaha mencari konsensus atau mengambil keputusan mengenai tidakan apa yang akan diambil. Oleh karena itu dalam FGD digunakan pertanyaan open-ended, yang memungkinkan responden untuk memberikan jawaban yang disertai dengan penjelasan-penjelasan.

Pertanyaan-pertanyaan yang disampaikan oleh peneliti adalah sekitar bagaimana kesiapan guru sekolah dasar dalam melaksanakan pembelajaran matematika yang berbasis pendidikan berkarakter, yaitu: (1) Bagaimana wawasan/pengetahuan guru tentang konsep pendidikan berkarakter? (2) Bagaimana kesiapan guru dalam mengimplementasikan pendidikan berkarakter khususnya pada proses pembelajaran matematika? dan (3) 
Bagaimana pendapat guru-guru tentang hambatan dalam mengimplementasikan proses pembelajaran yang berbasis pendidikan karakter, khususnya pada mata pelajaran matematika?

\section{HASIL PENELITIAN DAN PEMBAHASAN}

Data penelitian dari hasil diskusi melalui $F G D$ merupakan jawaban dan pernyataan dari responden (guru-guru sekolah dasar), namun jawaban dan pernyataan tersebut bervariasi, sehingga dilakukan editing, yaitu diseleksi dan diklasifikasi serta disusun oleh peneliti menjadi jawaban yang kalimatnya tersusun menjadi kalimat yang mudah dipahami dan ditafsirkan oleh pembaca. Data temuan hasil penelitian yang dimaksud secara garis besar adalah sebagai berikut:

\section{Wawasan/pengetahuan guru, tentang konsep pendidikan karakter.}

Sebagian besar guru-guru hanya mengetahui 3 (tiga) kebijakan pemerintah, yang berkaitan dengan pembinaan pendidikan berkarakter, yaitu: (1) UU RI No. 20 Tahun 2003 Tentang SISDIKNAS pasal 3; (2) PERMENDINAS No. 22 tahun 2006 tentang standar isi; dan (3) PERMENDIKNAS No. 23 tahun 2006 tentang SKL. Hal ini menunjukkan bahwa guru-guru sangat tidak cukup dalam memiliki wawasan mempersiapkan diri untuk melaksanakan pembelajaran yang berbasis pendidkan berkarakter.

Setidaknya ada empat kebijakan produk pemerintah yang semestinya dipahami guru-guru agar memiliki kesiapan untuk meng-implementasikan program pendidikan berkarakter, yaitu: Undang-undang RI Nomor 20 tahun 2003 tentang Sistem Pendidikan Nasional ( Pemerintah Republik Indonesia, 2003); Kebijakan Nasional Pembangunan Karakter Bangsa Tahun 2010-2025 (Kementrian Koordinator Kesejahteraan Rakyat, 2010); Desain Induk Pendidikan Karakter (Kementrian Pendidikan Nasional, 2010); dan Pengembangan Pendidikan Budaya dan Karakter Bangsa (Kementrian Pendidikan Nasional, 2010).

Apabila guru-guru di sekolah dasar memahami buku 'Desain Induk Pendidikan Karakter (2010)', guru akan memiliki wawasan tentang fungsi, tujuan dan ruang lingkup pendidikan berkarakter. Pada buku 'Kebijakan Nasional Pembangunan Krakter Bangsa 2010-2025', guru akan mengetahui tentang strategi pembangunan karakter bangsa melalui pendidikan. Dan pada buku 'Pengembangan Pendidikan Budaya dan Karakter Bangsa 
(2010)', guru akan memiliki wawasan secara detil tentang nilai-nilai karakter yang harus dikembangkan ketika akan melaksanakan proses pembelajaran.

\section{Pengalaman guru-guru dalam mengimplementasikan pendidikan berkarakter pada proses pembelajaran matematika.}

Ada berbagai informasi yang didapat dari guru-guru, berkaitan dengan pengalamannya dalam mengajar matematika.

Pertama. Ketika mengajar mata pelajaran matematika, pesertadidik disiapkan terlebih dahulu, agar mereka tertib selama belajar. Peserta didik diminta untuk memperhatikan apa yang akan disampaikan oleh gurunya. Setelah penjelasan selesai, diberikan latihan soal dari apa yang telah dipelajarinya. Peserta didik diminta untuk tertib dalam mengerjakan soal dan tidak diperbolehkan untuk melihat pekerjaan temannya. Kemudian diminta untuk mengumpulkan hasil pekerjaan mereka. Bagi yang belum dapat menjawab dengan benar, guru memanggilpeserta didik tersebut, untuk memberitahukan kesalahannya, sehingga dalam mengerjakan soal berikutnya diharapkan bisa mengerjakan soal lebih baik.

Kedua. Setiap hari sebelum pulang, guru melatih peserta didik untuk membiasakan disiplin dan mandiri.Semua peserta didik diharapkan memberikan jawaban operasi perkalian, tanpa adannya keributan, duduk dengan tenang menjawab dengan benar, tidak boleh menjawab sebelum ditunjuk oleh guru, seandainya tidak mengikuti aturan, walaupun jawaban benar tidak boleh pulang dulu, dan apabila ada aturan yang dilanggar, guru merubah pertanyaan dengan tahapan yang dilakukan setiap hari, mereka sudah terbiasa disiplin setiap akan pulang sekolah atau ke luar kelas.

Ketiga, Sebelum proses pembelajaran matematika dimulai, guru memberikan nasihat. Nasihat guru diantaranya: tidak boleh mencontek; harus berbuat jujur, percaya pada diri sendiri; tekun; dan disiplin.

Keempat, Setiap memulai kegiatan belajar melakukan doa terlebih dahulu. Berdoa dipimpin peserta didik secara bergiliran setiap hari, agar siswa menjadi berani untuk maju ke depan kelas. Peserta didik belajar untuk bertanggungjawab bila melakukan kesalahan. Bila ada siswa yang berkelahi, harus segera berdamai dengan cara saling bersalaman. dan meminta maaf dengan cara saling bersalaman dan meminta maaf satu sama lain. 
Pada umumnya guru-guru sekolah dasar sudah melaksanakan pembelajaran yang memuat pembentukan karakter, namun mereka melaksanakannya masih menggunakan cara-cara lama (konvensional). Hal ini dikuatirkan tidak sistematis, sehinggatidak akan mencapai sasaran tujuan pendidikan berkarakter yang semestinya, sebagai hasil rumusan para ahli yang telah tersusun dalam berbagai pedoman.

Merujuk dari Nik (2009), bahwa matematika tidak sekadar mengandung nilai matematika, tapi mengandung nilai pendidikan umum dan nilai pendidikan matematika. Dan pada konsep kurikulum nasional (kurikulum 2013) dijelaskan bahwa pemuatan pembentukan karakter peserta didik harus diintegrasikan pada setiap proses pembelajaran pada setiap mata pelajaran. Khususnya yang berkaitan dengan mata pelajaran matematika, harus diintegrasikan pada setiap kompetensi dasar.

Tabel di bawah ini merupakan contoh keterkaitan antara kompetensi dasar mata pelajaran matematika dengan nilai karakter peserta didik yang harus dikembangkan oleh guru pada proses pembelajaran matematika di sekolah dasar.

Tabel 1.

Keterkaitan Kompetensi Dasar Matematika Dengan Nilai Karakter

\begin{tabular}{|c|c|c|}
\hline NO & KOMPETENSI DASAR & NILAI KARAKTER \\
\hline 1 & $\begin{array}{l}\text { Mengenal bilangan asli sampai } 99 \text { dengan } \\
\text { menggunakan benda-benda yang ada di } \\
\text { sekitar rumah }\end{array}$ & $\begin{array}{l}\text { Ketelitian dan Bekerja } \\
\text { sama }\end{array}$ \\
\hline 2 & $\begin{array}{l}\text { Mengenal bangun datar dan bangun rung } \\
\text { menggunakan benda-benda yang ada di } \\
\text { sekitar rumah, sekolah, atau tempat bermain }\end{array}$ & Ketelitian dan disiplin \\
\hline 3 & $\begin{array}{l}\text { Menentukan urutan berdasarkan panjang } \\
\text { pendeknya benda, tinggi rendahnya tinggi } \\
\text { badan, dan urutn kelompok berdsarkan } \\
\text { jumlah anggotnya. }\end{array}$ & $\begin{array}{l}\text { Disiplin, Ketelitian, dan } \\
\text { Kerjasama }\end{array}$ \\
\hline 4 & $\begin{array}{l}\text { Membentuk dan menggambar bangun baru } \\
\text { dari bangun-bangun datar atau pola bangun } \\
\text { datar yang sudah ada. }\end{array}$ & $\begin{array}{l}\text { Kesabaran, disiplin dan } \\
\text { kerjasama }\end{array}$ \\
\hline
\end{tabular}

\section{Pendapat guru-guru tentang hambatan dalam mengimplementasikan proses pembelajaran yang berbasis pendidikan berkarakter.}

Pertama,lingkungan tempat tinggal peserta didik tidak mendukung keberlangsungan proses pendidikan karakter dengan maksimal, dan kesibukan orang tua menjadi alasan tidak terjadinya komunikasi antara guru dengan orang tua peserta didik. 
Kedua, pengaruh produk teknologi yang banyak digunakan anak-anak pada umumnya, dan banyaknya tontonan terutama televise, lebih banyak memperlihatkan budaya barat dibandingkan budaya bangsa sendiri.

Ketiga, guru terlalu banyak diberikan tugas-tugas yang bersifat administratif, sehingga tidak fokus memperhatikan perkembangan anak secara individual.

Keempat, guru merasa belum bisa memilih pokok bahasan matematika dengan nilai karakter yang relevan, sebab belum pernah mendapat arahan dari ahli yang bisa meningkatkan kompetensi dalam hal tersebut. Misalnya materi mana yang bisa membentuk karakter tekun, teliti, atau pantang menyerah.

Hambatan guru-guru untuk mengimplementasikan proses pembelajaran untuk membentuk karakter peserta didik, semestinya tidak perlu ada lagi apabila dimulai dengan niat yang kuat dari guru-guru untuk merubah mindset mengajar. Namun hambatanhambatan yang telah disampaikan oleh guru-guru sekolah dasar sangatlah rasional, sebab untuk membentuk karakter peserta didik tidaklah cukup hanya ditangani oleh guru-guru. Sebagaimana yang telah dijelaskan pada gambar konsep strategi pendidikan karakter secara mikro, keterlibatan pihak-pihak yang lainnya tidak bisa dilepaskan dari tanggungjawabnya dalam mengimplementasikan proses pembelajaran yang berbasis pendidikan berkarakter. Pihak-pihak lain yang dimaksud adalah Kepala Sekolah dan orang tua. Setidaknya menjadi keaharusan adanya komunikasi, kebersamaan, dan rasa tanggungjawab bagi guru, kepala sekolah dan orang tua.

\section{KESIMPULAN DAN SARAN}

\section{Kesimpulan}

Sebagaimana yang tersurat pada Undang-Undang Republik Indonesia Nomor 20 Tahun 2003 tentang Sistem Pendidikan Nasional Bab II Pasal 3, bahwa Pendidikan nasional bertujuan untuk berkembangnya potensi peserta didik agar menjadi manusia yang beriman dan bertaqwa kepada Tuhan Yang Maha Esa, berakhlak mulia, sehat, berilmu, cakap, kreatif, mandiri, dan menjadi warga negara yang demokratis serta bertanggungjawab. Oleh sebab itu, proses pembelajaran di sekolah harus berbasis pendidikan berkarakter.

Pada faktanya, guru-guru sekolah dasar dalam mengimplementasikan proses pembelajaran yang berbasis pendidikan berkarakter, belum siap untuk merubah mindset 
dari mengajar konvensional, yaitu mengajar dengan hanya melibatkan kompetensi peserta didik dari aspek moral knowing (kognitif) saja dan mengabaikan moral feeling (afektif) dan moral action (psikomotor). Fakta ini didapatkan dari studi kasus terhadap guru-guru sekolah dasar di kota Karawang Jawa Barat, khususnya mata pelajaran matematika.

\section{Saran}

Agar guru-guru sekolah dasar memiliki kesiapan untuk mengimplementasikan pembelajaran yang berbasis pendidikan karakter, dipandang perlu untuk melakukan kajian konsep dan kebijakan pendidikan karakter, yaitu: Kebijakan Nasional Pembangunan Karakter Bangsa Tahun 2010-2025 (Kementrian Koordinator Kesejahteraan Rakyat, 2010); Desain Induk Pendidikan Karakter (Kementrian Pendidikan Nasional, 2010); dan Pengembangan Pendidikan Budaya dan Karakter Bangsa. (Kementrian Pendidikan Nasional, 2010).

Khusus untuk guru-guru sekolah dasar yang mengajar mata pelajaran matematika, dipandang perlu untuk meningkatkan kompetensinya dengan melakukan kajian teori konsep dasar matematika. Sebab dengan melakukan kajian konsep dasar matematika guruguru akan memiliki wawasan atau pengetahuan untuk menghubungkan antara matematika dengan nilai-nilai karakter yang sesungguhnya telah tertuang dalam matematika.

\section{E. DAFTAR PUSTAKA}

Krueger, R. A. (1988). A Practical Guide for Applied Research. California: SAGE Publications.

Kementrian Pendidikan Nasional. (2010). Pengembangan Pendidikan Budaya dan Karakter Bangsa. Jakarta : Badan Penelitian dan Pengembangan Pusat Kurikulum

Lickona,T. (1992). "Educating for Character: How Our School Can Teach Respect \& Responsibility". New York: Bantam Book

Nuh, M. (2010). Desain Induk Pendidikan Karakter. Jakarta: Kementrian Pendidikan Nasional RI

Nik Pa, N.A (2009). Nilai dan Etika dalam Pendidikan Matematika. Kuala Lumpur: Universitas Malaya

Soedjadi, R.(2000). Kiat Pendidikan Matematika di Indonesia (Konstatansi Keadaan Masa Kini Menuju Harapan Masa Depan). Jakarta : Dirjen Dikti Depdiknas. . 2003. Undang-Undang Republik Indonesia Nomor 20 Tahun 2003 Tentang Sistem Pendidikan Nasional. Jakarta: Pemerintah Republik Indonesia 